\title{
Knowledge Networking for Family Planning: The Potential for Virtual Communities of Practice to Move Forward the Global Reproductive Health Agenda
}

\author{
Megan O'Brien, MHS* \\ Center for Communication Programs \\ Johns Hopkins University \\ 111 Market Place, Suite 310, Baltimore, MD 21202, USA \\ E-mail: mlobrien@jhuccp.org \\ *Corresponding author

\section{Catherine Richey} \\ E-mail: richeyc@who.int
}

\begin{abstract}
This paper highlights experience from five years of using virtual communication tools developed by the World Health Organization Department of Reproductive Health and Research (WHO/RHR) and its partners in the Implementing Best Practices (IBP) in Reproductive Health Initiative to help bridge the knowledge-to-practice gap among family planning and reproductive health professionals. It explores how communities of practice and virtual networks offer a unique low-cost way to convene public health practitioners around the world to share experiences. It offers examples of how communities of practice can contribute to the development and dissemination of evidencebased health information products, and explores the potential for online networking and collaboration to enhance and inform program design and management. The paper is intended to inform the reproductive health community, as well as others working in health and development, of the potential for using virtual communities of practice to work towards achieving common goals and provide some examples of their successful use.
\end{abstract}

Keywords: Virtual Collaboration, Reproductive Health, Knowledge Sharing, Knowledge Networking, Community of Practice.

Biographical notes: Megan O'Brien is a Communications Associate with the Knowledge for Health (K4Health) Project based at Johns Hopkins University's Center for Communication Programs (JHU/CCP). She is devoted to reproductive and women's health and has a Master of Health Sciences from the Johns Hopkins Bloomberg School of Public Health and a Bachelor of Arts from Emory University.

Catherine Richey holds a Master of Public Health with a concentration in Women's and Reproductive Health from the Johns Hopkins Bloomberg School of Public Health and a Bachelor of Arts in Anthropology from Vassar College. 


\section{Introduction}

The recent 15-year anniversary of the International Conference on Population and Development (ICPD) has given the global reproductive health community an opportunity to reflect on its progress towards meeting the reproductive health needs of women and couples worldwide and to renew their commitment to meet the goals outlined at ICPD. Although the impact of family planning and reproductive health programs over the past five decades has been tremendous, numerous challenges remain (Cleland, 2006). An estimated 201 million women in developing countries have unmet need for contraception (Sonfield, 2006), a woman's lifetime risk of dying due to pregnancy and childbirth in developing countries is one in 75 (WHO, 2007), and about 7,400 adults and children worldwide become infected with HIV daily (UNAIDS, 2008).

Thanks to a considerable body of knowledge on evidence-based reproductive health practices and increased access to a wide array of health technologies, the global reproductive health community has a good understanding of what needs to be done to improve these health outcomes. One challenge is to effectively transfer evidence into practice. A knowledge-to-practice gap continues to exist as many health care workers lack the up-to-date evidence-based information they need to make informed decisions and provide effective care. Equipping health care workers with the latest information, tools, resources, and a venue for ongoing discussion will contribute to improving family planning and reproductive health outcomes.

Virtual communication and networking offer a unique low-cost way to work towards closing the knowledge-to-practice gap. Virtual communication methods, known as "communities of practice," bring together geographically dispersed health workers who share common goals and face similar obstacles, yet rarely or never have the opportunity to collaborate in person. Etienne Wenger, a founding father of Social Learning Theory who has worked extensively in the field of communities of practice, states:

A community of practice is not merely a club of friends or a network of connections between people. It has an identity defined by a shared domain of interest. Membership therefore implies a commitment to the domain, and therefore a shared competence that distinguishes members from other people (Wenger, 2006).

These online communities provide a venue for developing and disseminating evidence-based health information products and services, facilitating the sharing of information and experience, and informing health guidance and policy.

\subsection{Using Virtual Communication Tools to Close the Knowledge-to Practice Gap}

Since 2002, the Implementing Best Practices (IBP) in Reproductive Health Initiative - a consortium of international reproductive health agencies, led by the World Health Organization's Department of Reproductive Health and Research (WHO/RHR) and the United States Agency for International Development (USAID) - has been exploring how virtual collaboration tools and workspaces can help close the knowledge-to-practice gap among public health professionals working in family planning/reproductive health. The IBP Partnership was founded by WHO/RHR and USAID ten years ago in collaboration with 8 partner organizations, including Johns Hopkins University's Center for Communication Programs (JHU/CCP). Since then, the partnership has grown to include 32 international reproductive health agencies. 
The objectives of the IBP Initiative are to improve access to reproductive health through the introduction, adaptation, implementation and scaling-up of best practices.

To facilitate achieving these goals, WHO designed a dynamic electronic communication tool to support communities of practice called the Implementing Best Practices (IBP) Knowledge Gateway. The Knowledge Gateway was developed to provide reproductive health professionals around the world access to the information they need, at the time they need it, and a venue in which they can immediately share local and international experience in order to improve reproductive health programs. The development of the Knowledge Gateway platform has enabled rapid large-scale information exchange and transfer within the reproductive health community that was not previously possible. As Royall et al. (2005) state, "The information technology evolution is creating new opportunities for the delivery of research information and education materials. Innovative and thoughtful applications of this new technology can increase the consistency, reliability, and quality of information shared" (Page 1).

\subsection{The IBP Knowledge Gateway}

The Knowledge Gateway is an easy-to-use tool that provides members with an online "space" where they can participate in virtual communities of practice, or "knowledge networks," focused on a variety of reproductive health topics. It uses a low-resolution electronic platform that is easily accessible in areas with both low and high Internet bandwidth. Membership is free and users can access the Knowledge Gateway through email with direct links to Web-based workspaces which contain a community library, discussion board, announcement board, and community calendar. Communication in Knowledge Gateway communities of practice is asynchronous, allowing members to participate at their convenience. Users can create their own communities of practice or join established ones and discuss issues, experiences, and lessons learned from their family planning/reproductive health programs. Members are also increasingly using the Knowledge Gateway to support virtual working groups that use the platform to work collaboratively on a specific activity.

The Knowledge Gateway provides an opportunity for a diverse group of reproductive health professionals such as program managers, doctors, nurses, midwives, and community health workers to communicate across geographically disparate settings. The ability to communicate quickly and easily also facilitates more rapid sharing and scale-up of sound technical and programmatic approaches. The Knowledge Gateway also removes significant barriers that often hinder communication among reproductive health professionals who work in various geographical locations and at different level of the health system.

Since its creation in 2004, membership in the Knowledge Gateway has grown from 300 to over 17,850 members from 215 countries and territories who participate in over 400 communities (Fig. I: Knowledge Gateway Development Timeline). The electronic platform supporting the Knowledge Gateway is now being shared with other international and country-based organizations and agencies working in health and development, enabling them to customize, brand, and manage their own communities. The simple low-resolution technology used by the Knowledge Gateway is proving to be a best practice for supporting virtual communities. In 2009, the Knowledge Gateway technology was being used by 170,000 individuals around the world, making it the largest online communication platform in the field of health and development. 


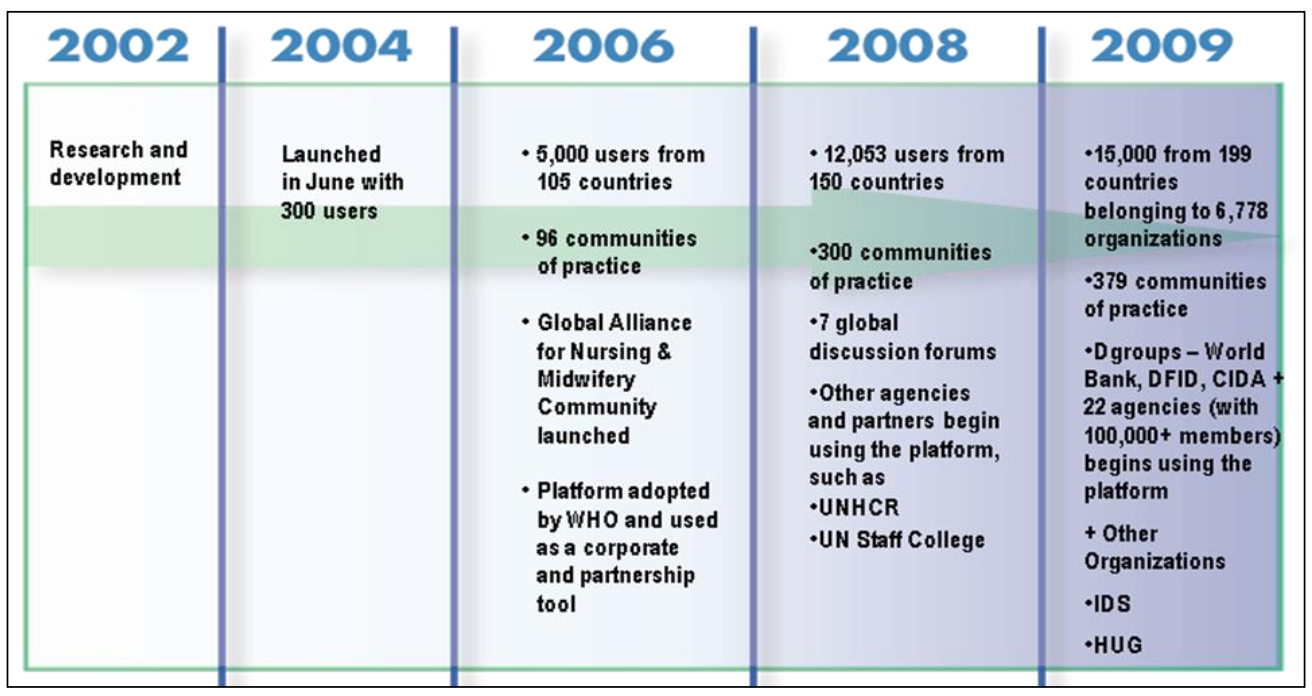

Figure I. Knowledge Gateway Development Timeline

\section{Snapshots of Communities of Practice and Global Discussion Forums}

Virtual communities of practice are not only venues for discussion, but also tools to disseminate health information and capture feedback. WHO/RHR has created several communities on the Knowledge Gateway focused on specific and tangible goals, such as creating linkages to access information about human resources for health and compiling reactions and responses to the launch of the WHO report, Atlas: Nurses in Mental Health 2007.

WHO/RHR, USAID, and IBP partner organizations have conducted over 15 global discussion forums focused on specific family planning/reproductive health topics on the Knowledge Gateway since 2005, as well as numerous community-specific discussions. More than 6,000 people have registered for these forums, which are considered "global" because all members of the Knowledge Gateway are invited to participate. The purpose of these forums is to provide opportunities to create synergy between exchanging best practices in reproductive health, country-based and personal experiences, and resources and knowledge. Key objectives of global discussions include facilitating dialogue among public health professionals; providing a venue for virtual collaboration among practitioners in the field and giving participants an opportunity to interact with experts on the topic; strengthening online communities within the Knowledge Gateway; creating and strengthening partnerships among participants; and supporting the improvement of reproductive health outcomes. The following four examples provide snapshots of a selection of these global discussions. 


\subsection{Postpartum Family Planning Community of Practice}

ACCESS-FP, based at Jhpiego (an IBP partner affiliated with Johns Hopkins University), created the Postpartum Family Planning Community primarily as a way to facilitate ongoing exchange among individuals who met during a technical consultation in November 2007. This community of practice was created in January 2007 and is now open to anyone interested in learning about and exchanging information, tools, and resources related to postpartum family planning. To galvanize discussion, ACCESS-FP conducted six virtual global discussions on the following topics related to postpartum family planning from March 2007 through October 2009, including:

- $\quad$ Lactational Amenorrhea Method and the Transition to Other Modern Methods of Family Planning (March 2007);

- Healthy Timing and Spacing of Pregnancy (November/December 2007);

- Key Messages for Postpartum Family Planning (April 2008);

- Postpartum Family Planning Contraceptive Technology (September 2008);

- $\quad$ Strategies for Community-Based Postpartum Family Planning (March 2009); and

- $\quad$ Postpartum Intrauterine Contraceptive Devices (October 2009).

These six forums increased membership in the community of practice three-fold between March 2007 and October 2009, from 190 people in 36 countries to 664 people in 71 countries. For each one- to two-week discussion, communities of practice leaders called upon postpartum family planning experts to kick off discussions and pose and answer questions raised by participants.

In addition to the global discussions, a variety of other activities take place in the Postpartum Family Planning Community. For example, the Lactational Amenorrhea Method Working Group which conducts periodic face-to-face meetings has used this community to share country-level perspectives on the lactational amenorrhea method of contraception. The discussion on postpartum intrauterine contraceptive devices also resulted in the formation of a working group around the topic. The questions raised during the forum also will offer some content and context for the working group to focus on in the future.

\subsection{Family Planning: A Global Handbook for Providers Global Discussion Series}

From October 2007 to May 2008, the INFO Project in collaboration with WHO/RHR, USAID, and the IBP Consortium, organized and co-sponsored seven global discussions on contraceptive methods highlighted in the recent publication, Family Planning: A Global Handbook for Providers. Prepared through a unique collaboration among WHO/RHR, USAID, JHU/CCP and technical experts from over 30 organizations around the world, this handbook is one of WHO's four cornerstones of family planning guidance. The online discussion series involved many of the organizations who helped to develop the handbook and covered topics, including:

- Bringing New People to Family Planning: The Broader Impact of The Fertility Awareness Approach, sponsored by the INFO Project and the Institute for Reproductive Health (October/November 2007);

- $\quad$ Strengthening Service Delivery and Counseling for Injectable Contraceptives, sponsored by the INFO Project (November 2007); 
- Contraceptive Implants, sponsored by the INFO Project, Family Health International, Population Council, and ACQUIRE Project/EngenderHealth (January/February 2008);

- Intrauterine Devices (IUDs): Contraception or Controversy? sponsored by the INFO Project, Population Council, and ACQUIRE Project/EngenderHealth (February 2008);

- Female and Male Sterilization, sponsored by the INFO Project, Family Health International, and ACQUIRE Project/EngenderHealth (March 2008);

- Female and Male Condoms, sponsored by the INFO Project, PATH, and CHANGE (April 2008); and

- Cervical Barrier Methods, sponsored by the INFO Project, PATH, and IBIS Reproductive Health (June 2008)

The two-week discussions took place in topic-specific communities of practice in the Knowledge Gateway that were created to disseminate evidence-based information and up-to-date guidance on contraceptive methods. Registration and participation statistics for these forums can be found in Table 1: Registration and Participation Statistics for the Family Planning: A Global Handbook for Providers Online Discussion Series. Overall, an average of 194 individuals from 41 countries participated in each discussion forum and sent an average of 34 contributions - 61\% from developing countries.

Table 1. Registration and Participation Statistics for the Family Planning: A Global Handbook for Providers Online Discussion Series

\begin{tabular}{|l|l|l|l|l|}
\hline & $\begin{array}{l}\text { Number of } \\
\text { forum } \\
\text { registrants }\end{array}$ & $\begin{array}{l}\text { Number of } \\
\text { participating } \\
\text { countries }\end{array}$ & $\begin{array}{l}\text { Number of } \\
\text { contributions }\end{array}$ & $\begin{array}{l}\text { Percent of } \\
\text { contributions } \\
\text { from } \\
\text { developing } \\
\text { countries }\end{array}$ \\
\hline $\begin{array}{l}\text { Bringing New } \\
\text { People to Family } \\
\text { Planning }\end{array}$ & 225 & 40 & 58 & $79 \%$ \\
\hline $\begin{array}{l}\text { Strengthening } \\
\text { Service Delivery and } \\
\text { Counseling for } \\
\text { Injectable } \\
\text { Contraceptives }\end{array}$ & 80 & 25 & 38 & $40 \%$ \\
\hline $\begin{array}{l}\text { Contraceptive } \\
\text { Implants }\end{array}$ & 225 & 46 & 31 & $45 \%$ \\
\hline $\begin{array}{l}\text { IUDs } \\
\text { Female \& Male } \\
\text { Sterilization }\end{array}$ & 69 & 48 & 22 & $95 \%$ \\
\hline $\begin{array}{l}\text { Female \& Male } \\
\text { Condoms }\end{array}$ & 500 & 72 & 22 & $80 \%$ \\
\hline $\begin{array}{l}\text { Cervical Barrier } \\
\text { Methods }\end{array}$ & 84 & 31 & 20 & \\
\hline
\end{tabular}

$\dagger$ - Took place in an existing FC community 
The co-sponsoring organizations provided subject matter experts for each discussion and collaborated on all postings that were sent to participants. Throughout the discussion, experts and facilitators highlighted and shared evidence-based guidance related to contraceptive methods that is found in the Global Handbook. Post-forum evaluations indicate that $91 \%$ of forum participants were very or somewhat satisfied with the content of the discussions. This series of online discussions was valuable for eliciting and capturing participant experiences about use of these contraceptive methods at country- and community-levels.

\subsection{Elements of Success in Family Planning Programming}

In December 2007, the INFO Project in collaboration with WHO/RHR and the IBP Consortium sponsored the global discussion forum, Elements of Success in Family Planning Programming. Prior to the launch of the discussion, members were invited to complete an online survey asking them to identify the top 10 program elements most important to the success of family planning programs. Approximately 500 health care professionals from 98 countries responded to the online survey. The objective of the forum was to discuss the survey results in more depth, focusing on key elements identified by survey respondents, and to share family planning program experiences and challenges with colleagues around the world. Nearly 300 family planning professionals in 63 countries joined the discussion.

Each day of the forum focused on one or two of the following elements that survey respondents had identified:

- Supportive policies

- Evidence-based programming

- Leadership and management

- Effective communication

- Contraceptive security

- Well-trained staff

- Client-centered care

- $\quad$ Easy access

- Affordable services

- Appropriate integration of services

Over the two week discussion, participants made 88 contributions. The most contributions came from India (18), Iran (8), Bangladesh (7), Canada (7), the US (6), and Senegal (6). The online discussion informed the subsequent development of a package of resources for family planning program managers aimed at strengthening these core elements of family planning programs.

\subsection{Reproductive Health Essential Medicines}

In June 2009, WHO/RHR and partners convened the online global discussion forum, Access to Reproductive Health Essential Medicines and Contraceptives: Why is it so Difficult to Achieve? The purpose of the forum was to bring together individuals working in programming with those working in procurement to discuss challenges and share best practices and lessons learned. 
Over the two-week discussion, nearly 400 participants from 74 countries addressed a number of provocative topics relating to supply security. The discussions included whether current policies are roadblocks to procurement, if product quality is an issue, how to better predict stock needs, and how to stop stockouts. A total of 100 contributions on these topics were received - nearly $80 \%$ of which came from participants in developing countries.

Upon completion of the discussion, the forum was evaluated through a short online survey $(n=50)$ and in-depth telephone interviews $(n=13)$. Over $90 \%$ of respondents reported being very satisfied or somewhat satisfied with the content of the discussion and that the forum definitely or somewhat met its goal of discussing the challenges related to access to reproductive health essential medicines. Most survey respondents reported that the discussion had significant impact on their work. Nearly $80 \%$ responded that they plan to use resources or practices discussed in the forum in their work. Forty-three percent read materials suggested in the discussion, and $41 \%$ reported planning to do so. Fifty-four percent of respondents forwarded forum postings to other people.

Forum evaluators also conducted 13 telephone interviews in English, French, and Spanish. The participants were from India (3), Kenya (2), Cameroon (2), Ethiopia (1), Pakistan (1), Nigeria (1), Haiti (1), East Timor (1), and Peru (1). The feedback from these interviews was very positive. When asked about their overall impression of the discussion, the majority of interviewees called it "very educational" and also remarked on the wide range of participation. A participant from India commented on the timeliness of the topic, and a participant from Pakistan remarked on the importance of tools such as this forum that can reach the grassroots level and bring people together around these important issues. A participant from East Timor also noted that "most of the participants faced similar challenges." Respondents were also asked to give examples of how they were using the information from the discussion in their work. A participant from Ethiopia stated that he will use information from the forum to help shape the Ethiopian government's upcoming assessment of reproductive health commodity procurement. Others also commented that learning best practices in procurement had helped them improve their performance in this area. For example, a participant from India is now using a new forecasting model which she hopes will reduce the incidence of stockouts.

\section{Value Added of Communities of Practice}

Rarely are communities of practice or global discussion forums convened on the Knowledge Gateway without a specific objective or end-product in mind. Although there is importance in simply exchanging ideas, experiences, and opinions, channeling these exchanges towards something more concrete - such as developing health information products that better meet audience needs, disseminating the latest evidence-based guidance, supporting or sustaining activities, or informing guidance and policy - has more value added. Working towards a tangible goal also gives participants the opportunity to contribute their voice to an outcome that is concrete and meaningful.

\subsection{Develop Health Information Products and Services}

In several instances, communities of practice have been used to help inform the development of health information products and services. Communities of practice offer the opportunity to quickly tap into the knowledge, experience, and opinions of health workers around the world, providing an ideal way to identify information needs of key 
audience groups. For example, the INFO Project used the Elements of Success in Family Planning Programming discussion (December 2007), along with a synthesis of available evidence-based information, to inform the development of a package of resources including a Web-based toolkit, a print publication, and an eLearning course. These products have been disseminated widely and used by thousands of family planning programmers around the world; 395 users from 52 countries participated in Web-based toolkit activities, 47,000 copies (some in English, Spanish, and French) of the print publication have been distributed around the world, and 460 learners have scored $85 \%$ or better on the Family Planning Programming: Elements of Success eLearning course. The information that was gathered during the online discussion helped make these resources more useful, usable, and user-friendly.

Similarly, WHO and partners are using the outcome of the Reproductive Health Essential Medicines global discussion forum referenced above to inform the development of an online information portal dedicated to reproductive health essential medicines. The portal will contain key documents, links, and guidance to support those working to ensure that reproductive health essential medicines are easily available.

\subsection{Disseminate Evidence-Based Health Information}

As mentioned above, membership in communities of practice on the Knowledge Gateway now exceeds 17,850 individuals. Those members come from 215 countries and territories and work in over 8,500 organizations around the world. The extensive membership and geographical and cultural diversity of members make a community of practice on the Knowledge Gateway a unique venue to disseminate evidence-based reproductive health information. In these communities of practice, it is possible to simultaneously inform a nurse in Indonesia, a midwife in Tanzania, and a professor in Ethiopia about new evidence-based reproductive health guidance. For example, in the forum titled Intrauterine Devices (IUDs): Contraception or Controversy? experts corrected participants' misunderstandings about copper-bearing intrauterine devices and reaffirmed that this contraceptive method does not make women infertile.

The virtual nature of communities of practice enables evidence-based health information to be disseminated quickly and efficiently. Given the high cost and long delivery time associated with shipping printed materials, virtual communities of practice offer a faster, more targeted, and more cost-efficient means of disseminating new information and guidance. Internet access is spreading rapidly and becoming more affordable around the world. For example from 2005 to 2007, Rwanda experienced a $300 \%$ increase in the number of Internet users (UNData, 2009). Because of this, virtual communication in communities of practice is becoming more viable and relied upon. Communities of practice also ensure that information quickly gets into the hands of those who need it, rather than passively posting a new guidance document on a Web site for people to find and read. Due to the virtual nature of these communities of practice, members can forward a message containing important reproductive health guidance to any colleague, whether or not they are a member of the community. These announcements can quickly enter and be passed though many virtual networks. On average, $51 \%$ of members who participated in the global discussion series on contraceptive methods in the Global Handbook reported forwarding discussion postings to a colleague. To sustain regular dissemination of family planning/reproductive health information, Knowledge Gateway managers send a weekly eNewsletter to all members of the IBP global community. Each newsletter contains new publications, tools, resources, guidance documents, and upcoming trainings and conferences related to family 
planning/reproductive health that have been submitted by IBP partner organizations and other international family planning/reproductive health organizations.

The Global Alliance for Nursing and Midwifery (GANM) community offers an example of how communities of practice on the Knowledge Gateway can aid the dissemination of tools and resources. Established in 2005 by WHO and its many nursing and midwifery collaborating centers, the GANM has brought increased attention to the vital role of nursing and midwifery in the global health agenda and now connects nearly 2,000 members from 140 countries, providing opportunities to exchange knowledge, fill information gaps, and share experiences. In 2009, a team from GANM and the Johns Hopkins University School of Nursing developed and disseminated via the GANM Community a downloadable educational module for use among globally dispersed nurses and midwives. The module, available in both English and Spanish, focuses on cervical cancer detection using visual inspection with ascetic acid, a simple inexpensive screening test designed for use in low-resource settings. Members of the GANM community are now able to download the free module and learn to conduct visual cervical cancer inspections using acetic acid (Johns Hopkins University School of Nursing, 2009).

\subsection{Facilitate Information Sharing}

Communication in a virtual community of practice is also multi-directional. Community of practice leaders can (and often do) initiate discussion on a specific topic; however, any member can post a message to other members of the community at any time. Also, during an organized discussion forum when subject matter experts are participating, any member can send a question or comment directly to an expert and receive a rapid response. By removing organizational and hierarchical barriers, communication in a community of practice can move more freely and in more directions, compared with face-to-face professional interaction.

As discussed above, in collaboration with WHO/RHR and USAID published Family Planning: A Global Handbook for Providers in 2007. The Global Handbook offers clinic-based health care professionals in developing countries the latest guidance on providing contraceptive methods. This book was developed through a unique collaborative process in which reproductive health experts around the world came to consensus on practical guidance that reflects the best available scientific evidence. More than 30 organizations collaborated on the creation of this handbook and all agreed to disseminate the Global Handbook (and its content) as widely as possible. To this effort, the INFO Project, WHO/RHR, USAID and IBP partners hosted the online discussion series discussed above. From October 2007 to May 2008, INFO collaborated with other international family planning/reproductive health organizations to co-sponsor seven oneto two-week forums to disseminate the evidence-based information contained in the Global Handbook.

In addition to the registration and participation statistics listed above, an average of $67 \%$ of participant contributions sent during each discussion forum was submitted from participants in developing countries. This is not unique to the Global Handbook discussion series. Results of post-forum evaluations indicate that online discussions provide a strong outlet for public health practitioners working in developing countries; community of practice members from such settings contributed the majority of the messages in 11 of 18 discussion forums held from 2005 to 2008 on the Knowledge Gateway. By simply logging into their community of practice, they can share their experiences, ask questions of colleagues working in similar technical areas, and seek help to overcome challenges they face in programs or service delivery. This type of interaction 
is especially important to those working in isolated or rural areas with limited opportunities to interact face-to-face with colleagues.

\subsection{Support and Sustain Activities}

Communities of practice can be a valuable tool to support ongoing initiatives, or maintain momentum of face-to-face meetings and facilitate next steps. In November 2009, over 1,300 reproductive health professionals assembled in Kampala, Uganda, for the International Conference on Family Planning: Research and Best Practices. Sponsored by the Bill and Melinda Gates Institute for Population and Reproductive Health at JHU/CCP, Makerere University's School of Public Health in Uganda, and the IBP Initiative along with other international and national partners, this conference highlighted research and best practices in family planning around the world. To capture and sustain the enthusiasm, knowledge, ideas, and activities of all who attended this conference, the Knowledge for Health (K4Health) Project, based at JHU/CCP, in collaboration with USAID, WHO/RHR, and other IBP partners, launched a new community of practice in January 2010 in which all Kampala attendees were invited to participate. This community of practice will serve as a global virtual community for anyone interested in international family planning and will contain sub-communities on specific family planning topics. In April 2010, 688 participants from 69 countries joined a global discussion forum on Increasing Family Planning Services to Improve International Family Planning Programs in this community of practice.

\subsection{Inform Program Guidance and Policy}

Communities of practice can also be used to inform program guidance and policy development and can lay important groundwork for face-to-face meetings. For example, in October 2007, WHO/RHR and UNFPA sponsored a virtual discussion focusing on the sexual and reproductive health needs of persons with disabilities in the Knowledge Gateway. The discussion engaged 98 participants from 26 countries. Following the discussion, a face-to-face International Expert Group Meeting was held in Brazil in December 2007. Information gathered from the virtual discussion was used as a basis for this Expert Group meeting which produced a draft of the now published guidance note, Promoting sexual and reproductive health for persons with disabilities (WHO 2009).

The Mental Health community on the Knowledge Gateway, which held a global discussion forum in 2007 with 615 participants from over 80 countries, offers another example of the potential for communities of practice to influence the global dialogue on a specific issue. The two-week discussion forum was organized around the findings from a survey of nursing mental health practices in 177 countries and territories and the recent publication, Atlas: Nurses in Mental Health (WHO, 2007). The suggestions and findings from the survey and online forum discussion demonstrated a strong interest in improving the mental health services that nurses provide and highlighted the need to improve both basic and specialized mental health training for nurses working in low- and middleincome countries. These outcomes, along with the Atlas for Nurses in Mental Health, are considered a call to action for the International Council of Nurses, WHO, and other international agencies (Barrett, 2009). 


\section{Next Steps}

As communities of practice and the technology that supports them continue to evolve, the IBP Initiative is committed to building a collective understanding of how virtual collaboration can strengthen service delivery by equipping health care workers with the relevant information they need to do their jobs. For example, when exploring how tools and resources that are highlighted and disseminated in communities of practice can be adapted to specific settings, the IBP Initiative learned that the WHO Eastern Mediterranean Regional Office has adapted a survey of the Elements of Success in Family Planning Programming to measure the status of family planning programming in the region.

The IBP Initiative will continue to conduct global discussions on family planning and reproductive health topics and will continue to evaluate them in order to improve future discussion. Moreover, WHO and JHU/CCP will periodically survey IBP members about satisfaction with the Knowledge Gateway platform and work to implement suggested enhancements. Given the growth in membership in recent years, WHO and JHU/CCP are beginning to expand the training opportunities for new users. They will be developing an eLearning course and associated resources to provide a more comprehensive and standard training package for those interested in participating in and/or managing communities of practice on the IBP Knowledge Gateway.

In an effort to explore the uptake and use of knowledge and information gained in an online discussion, JHU/CCP and WHO will begin conducting routine in-depth interviews with forum participants, forum facilitators, and guest experts. These interviews will provide further insight into how forum participants are using knowledge and resources shared in online forums in their professional activities, ways to strengthen the end-product and objectives of online discussions, as well as overall satisfaction with online forums and ways to improve them.

\section{Conclusion}

Online communities offer a relatively easy-to-use, inexpensive, and effective avenue to exchange information with colleagues around the world. Since 2005, discussions in virtual communities of practice in the Knowledge Gateway have focused on a range of family planning/reproductive health topics. These discussions have given participants especially those in less developed countries - access to evidence-based information, guidance, resources, and networking opportunities that they might not have had otherwise. As the number of Internet users continues to increase around the world, membership and activity in virtual communities of practice will continue to increase, as well. Using communities of practice to disseminate evidence-based health information, develop health products, facilitate information exchange, and to inform policy and guidance are all feasible ways of narrowing the knowledge-to-practice gap among reproductive health professionals, as well as among those working in other sectors of health and development.

\section{Acknowledgements}

The authors would like to thank Margaret Usher-Patel (WHO/RHR), Scientist in the World Health Organization Department of Reproductive Health and Research (WHO/RHR) and Implementing Best Practices Secretariat and Margaret D'Adamo, 
Knowledge Management/Information Technology Advisor, USAID, Office of Population and Reproductive Health..

\section{References}

1 Barrett, T., Boeck, R., Fusco, C., Ghebrehiwet, T., Yan, J., Saxena, S. (2009). Nurses are the key to improving mental health services in low- and middle-income countries. International Nursing Review, 56(1), 138-141.

2 Cleland, J., Bernstein, S., Ezeh, A., Faundes, A., Glasier, A., \& Innis, J. (2006). Family planning: The unfinished agenda. Lancet, 368( 9549), 1810-1827.

3 Johns Hopkins University School of Nursing. (2009). Webwise nurses harness new media for global health. News Release. Aug. 10, 2009. Retrieved from http://www.son.jhmi.edu/newsevents/news/news.aspx?ID=431

4 Royall, J., van Schayk, I., Bennett, M., Kamau, N. \& Alilio, M. (2005). Cross the digital divide: the contribution of information technology to the professional performance of malaria researchers in Africa. African Health Sciences, 5(3), 246254.

5 Sonfield, A. (2006). Working to eliminate the world's unmet need for contraception. Guttmacher Policy Review, 9, 1. Retrieved from http://www.guttmacher.org/pubs/gpr/09/1/gpr090110.html

$6 \quad$ World Health Organization (WHO). (2007). Maternal mortality in 2005: Estimates developed by WHO, UNICEF, UNFPA and the World Bank. Retrieved from http://www.who.int/whosis/mme_2005.pdf

7 UNAIDS. (2008). Report on the global AIDS epidemic. Retrieved from http://www.unaids.org/en/KnowledgeCentre/HIVData/GlobalReport/2008/2008_Gl obal_report.asp

8 UNData. (2009). Estimated internet users data. Retrieved from http://data.un.org/Data.aspx?d=ITU\&f=ind1Code\%3aI4212

9 Wenger, E.(2006). Communities of Practice: A Brief Introduction. Retrieved from http://www.ewenger.com/theory/index.htm

10 World Health Organization. (2007). Atlas: Nurses in Mental Health 2007. WHO, Geneva.

11 World Health Organization (WHO). (2009). Promoting sexual and reproductive health for persons with disabilities; WHO/UNFPA guidance note. WHO, Geneva. Retrieved from http://whqlibdoc.who.int/publications/2009/9789241598682_eng.pdf 